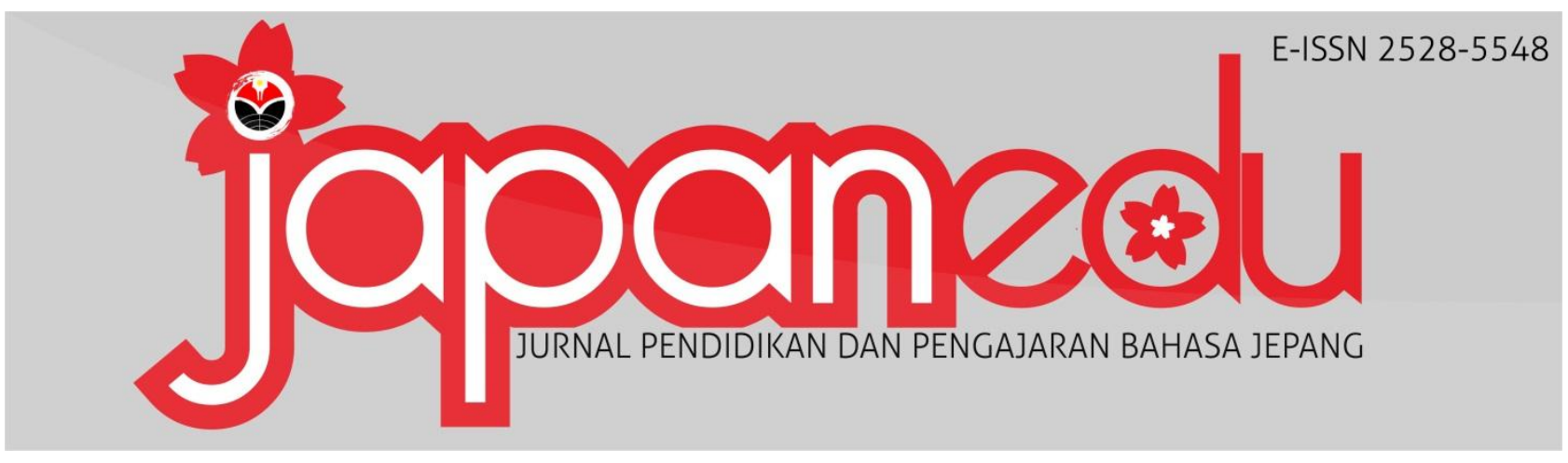

\title{
EFEKTIVITAS PENGGUNAAN MEDIA APLIKASI ALEPHBET KATAKANA UNTUK MENINGKATKAN KEMAMPUAN MENULIS HURUF KATAKANA
}

\section{(Studi Eksperimen Terhadap Siswa XI IPA I Tahun 2016-2017 SMA Pasundan 2 Bandung)}

\author{
Tiur Mian Siregar ${ }^{1 *}$, Renariah $^{2}$, Sudjianto $^{3}$ \\ ${ }^{1}$ Departemen Pendidikan Bahasa Jepang, Universitas Pendidikan Indonesia, Jl. Dr. \\ Setiabudhi No. 229, Bandung 40154, Indonesia \\ E-mail: tiurmiansiregar@gmail.com \\ Telp: +62822-1666-6547
}

\begin{abstract}
Abstrak
Penelitian ini dilatarbelakangi oleh minat siswa dalam pembelajaran bahasa Jepang. Siswa mengalami kesulitan dalam menguasai huruf hiragana dan katakana. Untuk mengatasi kesulitan tersebut, diperlukan alat atau media yang menarik dan praktis untuk membantu siswa dalam meningkatkan kemamapuan menulis huruf katakana. Berdasarkan hal tersebut penulis memberikan alternatif pembelajaran menulis katakana dengan menggunakan aplikasi Alephbet Katakana. Penelitian ini dilaksanakan sebanyak lima kali pertemuan menggunakan metode penelitian eksperimen kuasi dengan desain pre-test dan post-test. Adapun instrumen penelitian yang digunakan adalah test dan angket. Populasi dalam penelitian ini adalah seluruh siswa SMA Pasundan 2 Bandung tahun ajaran 2013/2014 dan sampel yang digunakan adalah siswa kelas XI IPA 1 berjumlah 24 siswa yang sedang belajar bahasa Jepang. Hasil dari analisis data diperoleh nilai mean pre-test adalah 18.13 dan nilai mean dari post-test adalah 88.23, dengan demikian terdapat peningkatan setelah treatment yaitu sebesar 70.1. Dan didapatkan nilai dari t hitung adalah 20.32 dan nilai t tabel dengan derajat kebebasan (db) yaitu 23 dengan taraf signifikan 5\% 2.07 dan 1\% 2.81. Dengan demikian nilai t hitung lebih besar dari t tabel $(20.32>2.07)$. Yang artinya dapat ditari kesimpulan bahwa terdapat perbedaan yang signifikan antara variabel $\mathrm{X}$ dan variabel $\mathrm{Y}$ sehingga hipotesis kerja ( $\mathrm{Hk}$ ) diterima dan hipotesis nol (Ho) ditolak. Berdasarkan hal tersebut dapat disimpulkan bahwa aplikasi Alephbet Katakana dapat membantu meningkatkan kemampuan menulis siswa dalam huruf katakana. Berdasarkan pengolahan hasil angket yang diperoleh dapat diketahui bahwa
\end{abstract}


sebagian besar siswa menyatakan merasa lebih mudah mempelajari huruf katakana dengan aplikasi Alephbet Katakana. Sebagai kesimpulan, aplikasi Alephbet Katakana dapat meningkatkan kemampuan siswa dalam menulis huruf katakana. Oleh karena itu, aplikasi Alephbet Katakana dapat dijadikan solusi sebagai metode pembelajaran huruf katakana.

Kata kunci : Menulis, Hiragana, Aplikasi

\section{Pendahuluan}

Manusia adalah hal penting penting dalam hidup dalam hidup dan dapat mencapai berbagai tujuan dengan kata-kata. Ini adalah sama dalam hal pendidikan. Elemen yang mengajarkan bahasa dalam pembelajaran di sekolah, misalnya, juga disertakan. Jadi, pada manusia, terutama dalam hal pendidikan, peran bahasa adalah penting, tetapi jika diabaikan, saya berpikir bahwa pendidikan tidak dapat dilakukan dengan baik.

Satu hal yang diperlukan untuk unsur kemampuan bahasa dalam pengajaran bahasa. kemampuan linguistik yang kuadrat, dan ada berbicara, mendengarkan, membaca dan menulis. Keempat kemampuan disatukan, bersatu, dan untuk memahami kemampuan mereka, peserta didik harus berlatih bahkan jika mereka hanya harus melakukannya. Bahkan di Jepang, peserta didik harus memahami kemampuan kuadrat agar pandai berbahasa Jepang.

Dalam perjalanan belajar bahasa Jepang, peserta didik harus memahami huruf sebagai Karakter dasar penting adalah elemen penting untuk mendukung kemampuan untuk menulis. Selain itu, surat harus diteliti benar-benar, untuk proses belajar bahasa Jepang yang baik. Ada beberapa karakter dalam bahasa Jepang. Hal ini Kanji Hiragana, Katakana, Lomasi. katakana studi dan hiragana dalam bahasa Jepang dasar. Pada awalnya, pelajar belajar Hiragana.
Berikutnya adalah Kataka. Dalam rangka untuk belajar Kanji, kedua karakter pada dasarnya perlu belajar.

Menurut Sudjianto dan Dahidi (2009), Hiragana memiliki bentuk seperti "" "い" " う" "え" "お". Hal ini dikatakan menulis surat-surat dari kurva. Katakana berbentuk seperti "A" "Aku" "C" "E" "O". Katakana dikatakan setiap karakter dari garis lurus gambar tersebut telah menjadi ciri armada.

Dalam penelitian ini, kami fokus pada metode penulisan katakana dalam penelitian ini seperti "shi" dan "tsu", "jadi" dan "n", "ko" dan "ku" Hal ini karena ada banyak karakter dan sulit untuk pelajar. Ketika belajar katakana, ada gambar yang metode mengajar tidak menarik, sehingga tampaknya ada beberapa gambar yang kelas Jepang sulit dipahami bagi peserta didik.

Dengan metode yang baik dalam proses pendidikan dan pembelajaran, peserta didik mendapatkan nilai bagus. Saya pikir media yang merupakan salah satu aplikasi Alephbet Katakana. Dalam aplikasi Alephbet Katakana, orang sering menggunakan visual dan auditori sensasi, gerakan dan nuansa.

SMA Pasundan 2 Bandung Ketika saya melatih untuk menjadi seorang guru yang saya punya pendidikan di Bandung SMA, saya belum pernah menggunakan tanda ini. Ini menjadi penyebab bahwa itu adalah 
terbatas pada instruksi manual dari tanda alat pengajaran. Untuk penelitian, mahasiswi sekolah kira-kira tinggi telah terganggu dengan menulis katakana. Untuk kelas kedua di SMA ada juga masalah yang sama Jadi untuk menganalisis yang meningkatkan kemampuan menulis katakana dalam aplikasi Alephbet Katakana (untuk menulis katakana dalam aplikasi Alephbet Katakana dengan tenaga kerja penelitian) Subjek adalah Pasundan 2 SMA kelas kedua, 2016 2017. judul penelitian ini adalah penelitian praktis pada SMA Pasundan 2 Bandung SMA kelas kedua, yang merupakan efek dari aplikasi Alephbet katakana untuk meningkatkan kemampuan menulis katakana adalah ada.

\section{Tujuan Penelitian}

Tujuan dari penelitian ini adalah sebagai berikut:

- Sebelum menggunakan aplikasi Alephbet Katakana, memutuskan kemampuan untuk menulis katakana.

- Untuk menentukan kemampuan untuk menulis katakana setelah menggunakan aplikasi Alephbet Katakana.

- Menentukan dampak penerapan Alephbet Katakana.

- Untuk menggunakan aplikasi Alephbet Katakana, memutuskan respon siswa.

\section{Metode Penelitian}

Metode penelitian yang digunakan dalam penelitian ini adalah eksperimen praktis. Desain penelitian ini adalah "desain pre-test dan post-test". Target audiens adalah SMA dari SMA Pasundan 2 Bandung di 2016/2017. sampel adalah 24 XI IPA 1 kelas. Dalam rangka untuk memperoleh data, itu adalah tes dan kuesioner. Tes dilakukan dua kali, pre-test dan post-test. Uji pendahuluan adalah untuk mengetahui kemampuan menulis katakana subjek sebelum menggunakan aplikasi Alephbet Katakana dan post test adalah untuk mengetahui hasil setelah menggunakan aplikasi Alephbet Katakana. Selain itu, kuesioner adalah untuk aplikasi Alephbet Katakana untuk mengetahui kesan dan kesan orang yang menjadi target. Desain penelitian ini adalah sebagai berikut.

\section{Temuan dan Pembahasan}

Dari analisis data, ditemukan bahwa t skor $=$ $20,32, \mathrm{db}=23$, uji $\mathrm{t}(5 \%) 2,07$, uji $\mathrm{t}(1 \%)=$ 2,07. Karena skor lebih tinggi daripada uji t, kami menerima pekerjaan sementara dan nol konstruksi sementara ditolak. Dengan kata lain, kemampuan untuk menulis katakana subjek sebelum menggunakan aplikasi Alephbet Katakana memiliki perbedaan yang signifikan dari kemampuan untuk menulis katakana subjek sebelum menggunakan aplikasi Alephbet Katakana.

Di sisi lain, seperti dalam hasil analisis kuesioner, lebih dari setengah dari subyek menggunakan aplikasi Alephbet Katakana untuk menulis katakana, mudah untuk memahami dan mengatakan itu menarik. Dan subjek dikatakan memiliki kemampuan ditingkatkan untuk menulis katakana. Dengan kata lain, orang yang menjadi target yang bersangkutan tentang aplikasi Alephbet Katakana.

\section{Kesimpulan}

Sebelum menggunakan aplikasi Alephbet Katakana, kemampuan rata-rata untuk menulis katakana subjek adalah 18,13 poin. Di sisi lain, setelah menggunakan aplikasi Alephbet Katakana, kemampuan rata-rata untuk menulis katakana subjek adalah 88,23 poin. Hasil penelitian menunjukkan bahwa kemampuan menulis katakana subjek setelah menggunakan aplikasi Alephbet Katakana 
lebih tinggi dari kemampuan untuk menulis katakana subjek sebelum menggunakan aplikasi Alephbet Katakana

Menurut analisis data, $\mathrm{t}$ signifikansi lebih tinggi dari uji t $(20,32>2,07)$, dan bekerja konstruksi sementara diterima dan nol sementara ditolak. Kemampuan menulis subjek 'katakana s setelah menggunakan aplikasi Alephbet Katakana ditemukan memiliki perbedaan yang signifikan dari kemampuan untuk menulis subyek' katakana sebelum menggunakan aplikasi Alephbet Katakana.

Menurut analisis dari data kuesioner, lebih dari setengah dari subyek menggunakan aplikasi Alephbet Katakana, tetapi dikatakan bahwa itu adalah mudah untuk memahami dan menulis katakana, itu menarik. Selain itu, target orang dikatakan telah meningkatkan kemampuan menulis katakana.
Aplikasi Alephbet Katakana dapat digunakan sebagai cara umum untuk mengajar katakana. Peserta didik dapat berkonsentrasi studi mereka dengan meningkatkan kemampuan mereka dengan cara siswa belajar. Kami akan melakukan penelitian lebih praktis dalam kelompok kontrol untuk menangkap hasil ini dengan hasil yang baik.

\section{Referensi}

[1] Depdikbud (2008) Kamus Besar Bahasa Indonesia Edisi Keempat. Jakarta: Gramedia.

[2] Sudjianto dan Dahidi, Ahmad. (2009) Pengantar Linguistik Bahasa Jepang. Jakarta: KBI

[3] Sutedi, Dedi. (2011) Penelitian Pendidikan Bahasa Jepang. Bandung: Humaniora 